\title{
Segmentation Choices
}

\section{Segmenting Markets and Selecting Segments}

Segmenting markets is a critical analytical step and directly related to the selection of target segments. The choice of a focus strategy as delineated in the previous chapter is a precursor to segmenting markets, related but different. The focus choice is a higher-order activity; segment selection is more granular. Just because a company settled on a given focus does not automatically determine the segment choice. Just as for focus choices, segment choices are needed to prevent resources from being spread over too many activities.

Many of the documented firms were very clear and specific about their chosen segments, just as they were equally clear about the type of segments in which they would not engage. The segment was sometimes delineated to separate industrial from consumer markets or distinguish between professional users and home users. In some instances, the selected segment was quite narrow, utilized for products with very specific requirements.

Focus does not eliminate the need for segmentation!

\section{Defining and Segmenting Market Space}

To give market segmentation traction, companies have to be able to define their market space in creative and penetrating ways in order to make sure that the selected segments are consistent with how the segment is defined. Time and time again, the successful firms in the research sample demonstrated that their market space definitions served as powerful drivers for their segment selection strategies. Felco, the producer of handheld shearing tools, offers a good example.

Felco segmented its market space neither by crop (such as grapes), nor by application (such as electrical industry) alone, but by the function performed by its tools. The tools were offered for right-handed or left-handed users. There were tools for lopping bigger branches, 
cable cutters, pruning saws, knives and even electric pruning shears. They included tools for electricians in the Netherlands, rose cutting in Ecuador, the garlic industry in the US or for cacao pruning, which took place twice annually and needed replaceable blades. Aside from function, particular attention was paid to ergonomics and user specifics: left hands and right hands, large hands and small hands and power-assisted tools were part of the portfolio as well. ${ }^{1}$

Initially, we were only responding to demand suggesting so many uses for our tools (Nicolet, CEO).

Defining its market around the cutting function, Felco could, over time, define a number of cutting segments based upon its experience, client contacts, and business development. The majority segment that became the focus for Felco activities led to many product variations, but all derived from a single source-the function of pruning.

Felco's product line for its main functional segments of pruning shears, loppers, cable cutters and pruning saws is extensive. For pruning shears alone, 24 different models were offered, and for loppers 14. Five different models of pruning saws were marketed. For the function of pruning and grafting, the company offered 13 knife models; power tools (three models) were also part of the product portfolio. Several accessories were included to complete the portfolio, from sharpening tools to holsters. ${ }^{2}$

Felco demonstrates an important Follow-On Strategy resulting from segment selection. Once targeted, many of the researched firms crammed their selected space, or segment, with a large variety of product versions. At Felco, it was 24 models of shears for one function, pruning, subdividing the segment users into several narrower categories, and producing models for each. For the lopping function, usually involving the use of both hands, 15 models were offered. This cramming strategy, often for small segments or market niches, was one of the recurrent practices observed by the firms in the sample.

The company also illustrates how the identification of a segment function with the final professional user - the worker in the vineyards - builds a strong connection to the product, creating a powerful customer franchise around a tool crucial to the vineyard worker. Adding additional accessories for the user complements the customer franchise and tends to create long-lasting bonds with him or her. In the final analysis, a company such as Felco comes to the point of owning the professional group using its tools.

In some circumstances, the market space can be defined around product characteristics, which can lead to further segmentation. Ricola, producer of herbal candy, defined its market around taste, as well as packaging features.

\footnotetext{
${ }^{1}$ Adapted from Felco company profile.

${ }^{2}$ Ibid.
} 
The Ricola assortment remained focused on its core herbal candy business segment. It consisted of two types: sugar and sugar free (sweetened with Stevia or artificially sweetened). The company offered some 25 different tastes but not all were sold in all markets. Aside from taste segmentation, Ricola offered its products in a wide variety of packaging alternatives that substantially added to the number of 300 to 400 Stock keeping units (SKUs) offered. $^{3}$

\title{
Subsegments to Define Target Customers
}

In the previous section about focus (Chap. 10), Jura served as an example of a company whose management changed its focus from being a full-line builder of small electric home appliances to a supplier of espresso machines for home use exclusively. The change of its focus did not stop there. A very specific segment was further targeted, in order for the company to distinguish itself from competing espresso machine makers.

\begin{abstract}
Jura focused on fully automated in-home coffee machines from ground coffee only, i.e. the bean-to-cup types. Other competitors, including SAECO, de Longhi, Krups and Nivona, all of them larger than Jura, also offered capsule-based machines; some were into small home appliances beyond coffee. When it came to the specific application segment, Jura focused strictly on the in-home-use segment and consistently stayed away from institutional markets, such as hospitals, restaurants, offices or canteens. More recently, some expansion has been observed into the area of small and selective office types, such as offices of law firms. Within its home segment, the focus was on the top segment. Jura aspired to offer exclusively the most demanding machines and left the low-priced machine segment to competitors. Jura was the only player in this field that operated such a clearly articulated segment strategy. ${ }^{4}$
\end{abstract}

Jura's segmentation experience demonstrates that a focus strategy alone does not eliminate the need for further segmenting the market in order to guide the effort to very specific customer segments. Although Jura is a company smaller than many of its larger, international competitors, it is the largest in its chosen segment. All of its marketing and sales activities are centered on its chosen segment. Absolute size of sales alone is not critical; the relative size in a chosen segment can determine market success.

Redefining its market space was also a factor at Pilatus which followed a unique approach to the areas of general aviation and pilot training aircraft. The company pursued two segments (government and general aviation), grew them over time, and connected the two via related technologies.

Government Aviation was Pilatus' initial segment and historically its largest one. This segment comprised its military training models, such as PC-7 MkII, PC-9 M and PC-21 military pilot trainers as well as complete support systems and simulators. The company claimed global leadership in this specific sector. Accounting for about 35 percent of sales,

\footnotetext{
${ }^{3}$ Adapted from Ricola company profile.

${ }^{4}$ Adapted from Jura company profile.
} 
deliveries to this sector were characterized by a different sales and decision-making structure. After some tests on an improved version of the PC-7, Pilatus embarked on the formal development of a new generation of training aircraft to replace both ageing generations of PC-7 fleets and the PC-9 models. Named PC-21, the first models were delivered in 2008. The PC-21 was intended as a new generation of flight trainer, allowing military pilots to do much of their training on a single trainer and move directly into fighter jets. This resulted in substantial cost savings as the flying conditions of a military jet could be experienced on the PC-21. For this to work, the cockpit layout of the plane allowed for the installation of advanced avionic configurations similar to those experienced in advanced military aircraft. ${ }^{5}$

The Pilatus approach to the military training market was unique. Where, initially, there were several segments, each comprised of ever more sophisticated aircraft, the company collapsed the three or four separate segments into a single one, developing a model that combined the functions spread over several previously separate segments. The market turned out to be oversegmented and presented an opportunity to agglomerate them into a single segment with substantial benefits for the government users.

Pilatus took a segmentation path that was completely opposite to that of the general aviation market. The company management realized that in between its main segment of supplying turboprop-powered single-engine aircraft, piloted by owneroperators, and the next level up, twin-jet executive aircraft, piloted by professionally licensed pilots, a significant market gap existed that could be exploited if the main aircraft characteristics of both existing segments could be combined, creating a new, third segment, in between.

Pilatus General Aviation segment included sales to the civil sector and comprised the large programs around the PC-12 turboprop single engine executive aircraft, with more than 1,700 planes delivered since 1994. The commercial and operational success of the PC-12 cemented Pilatus' reputation as a builder of general aviation aircraft. In feedback solicited from users for ideas for a next generation model, pilots requested more speed and range while keeping the rugged landing strip performance. Thus, Pilatus began development work in 2007 on a new model that was to result in the PC-24, a twin-engine small executive jet that retained much of the PC-12 turboprop performance. Powered by two rear-mounted jet engines and seating up to ten passengers, the cockpit was laid out for two pilots. However, the advanced cockpit configuration reduced pilot workload allowing for single pilot certification. The PC-24 was the first business jet equipped with a sizeable cargo door. Designed to operate from both short and unpaved airstrips, the PC-24 came equipped with landing gear to smooth out uneven surfaces and wheels to prevent sinking in on soft surfaces. ${ }^{6}$

The immediate resulting success in selling out the company's aircraft building capacity in record time signaled that spotting this new segment had been an excellent strategy.

\footnotetext{
${ }^{5}$ Adapted from Pilatus company profile.

${ }^{6}$ Ibid.
} 


\section{Playing the Product Features Game}

Two companies offer a view on how to play the product feature game once a general technology focus has been adopted. Both Rüeger and Sylvac concentrated on two different sectors of the measurement business. Having found that products could be used in a myriad of industrial and artisanal applications, both companies pursued a strategy of occupying the space with a large number of product variations and features.

Rüeger, offering a full range of temperature measuring instruments, expanded considerably beyond its original temperature gauges. To the bimetallic temperature gages gas thermometers, HVAC temperature gauges, thermometers for marine diesel applications and thermowells. More complex, further products included temperature probes with transmitters or multipoint sensors for use in many types of reactors. Temperature gauges represented more than 80 percent of company sales. Related to temperature instruments was a line of pressure gauges. And finally, the company also produced instruments on an OEM basis used mostly in the food industry. All of those products leveraged Rüeger's core technology around temperature gauges. In its application space, Rüeger offered one of the most extensive and differentiated product lines.

Sylvac, originally starting out with hand-held tools for measuring, had steadily innovated beyond calipers. Digital indicators were added, and the product line included micrometers, internal measurement instruments, measuring benches and height gauges. More recently, Sylvac pioneered the area of connected metrology offering Bluetooth connections for its tools. Scanners for optical measurement, ranging from vertical to horizontal and equipped with zooming, was a first step into the instrument or equipment segment with considerably higher price points. Sylvac developed its own software and electronics to go with all its tools and instruments.

Both Rüeger and Sylvac maintained extensive catalogs containing a large number of standard products. The Sylvac electronic product line alone covered some 300 pages of materials and specifications. Clearly, these companies practice the cramming game discussed earlier, competing on a maximum number of product variations. Invariably, playing this game leads to a complex supply chain and small batch production volumes.

\section{Targeting Multiple Segments}

As companies move their market coverage beyond a single segment, complexities increase. The move into multiple market segments need not be accomplished at once but might arise from business developments, or reactions to changing market conditions. Plumettaz is a case in point where the leading segments changed over times, and yet there was always a dominating segment supported by the company's core technology.

\footnotetext{
${ }^{7}$ Adapted from Rüeger company profile.
} 
Over its close to 100-year history, Plumettaz experienced significant shifts in the composition of its sales, all stemming from responses to opportunities in new market segments. Starting out in the food industry with packaging and labeling, the company moved heavily into the wine growing industry developing new equipment and pioneering the capstan-type winches. Learning how to mount winches on tractors, jeeps, or other vehicles, Plumettaz compensated the decline in the wine-growing segment with new equipment for lifting or pulling for non-agricultural applications. As the fiber optics opportunity developed, Plumettaz responded again and innovated beyond its core to develop cable-jetting skills. In 2018, Plumettaz sales to the Telecom industry amounted to about 60 percent, the other industrial applications accounted for about 25 percent of total sales. ${ }^{8}$

In the discussion of focus strategies, it was pointed out that firms who were able to leverage a single technology with multiple applications were well positioned to enter multiple segments. Such strategies were particularly successful when the additional cost of adding another application segment did not present a major hurdle.

At u-blox, it was soon found that the company's technology of embedding positioning and wireless communication into semiconductors for applications around GPS systems had great potential in many other sectors, both industrial and consumer. Confronted with such a crisis of opportunity at the company, a strategy had to be developed about how to go about the selection process in order to guide its business and set limits to prevent overextension.

The focus of u-blox was the segments of industrial, automotive and consumer applications. The industrial segment, about 55 percent of sales, included a wide range of applications, from fleet tracking, to cargo monitoring, street lighting, and to medical devices, based upon the company's 4G and 5G cellular systems-based modules. With the Internet of Things (IoT) appearing, volume in this segment was increasingly driven by this new megatrend. The automotive segment accounted for about 30 percent of company sales. The increasing technical requirements for $\mathrm{Cm}$-level-precision positioning and secure Vehicle-to-Everything Communication needs were driving this sector where u-blox was a leader in bringing new generations of products to market. Electric vehicles and autonomous driving were also dominant growth factors.

The consumer segment, accounting for about 10 percent of sales, was driven by an increasing demand for smart technology in sport and fitness equipment, people and pet trackers, action cameras and robotic lawnmowers, as well as consumer drones. Concerning the selection of applications and customer requests, the company needed a minimum of units per year to bring a new application on stream. As a result, u-blox did not focus on small unit applications. ${ }^{9}$

The challenge of making selection decisions around a company's crisis of opportunity such as chasing more segments than might be good for the business did not only occur at u-blox. Other firms, maxon, LEM, or EAO, for example, all faced similar issues.

\footnotetext{
${ }^{8}$ Adapted from Plumettaz company profile.

${ }^{9}$ Adapted from u-blox company profile.
} 
In the case of Sefar, it was a technology change in manufacturing, allowing the company to move from silk fabric to synthetics fibers, moving it beyond flour sieving, traditionally its major segment.

In the 1960s, synthetic fibers began to replace silk until finally, in 1990, the production of silk bag cloth was discontinued. It is possible to apply various chemical coatings on synthetic fibers, which meant that refinement was added as a new production step. The fields of application for Sefar fabrics became ever wider. Synthetic fibers, being superior to metal filters, allowed for filtration applications in the automotive industry. After great efforts, Sefar managed to make this area one of its most important business segments in the 21st Century. ${ }^{10}$

For Sefar, the target industries included the chemical, minerals, food, environmental, life science and machinery and equipment industries. The applications, or tasks to be performed, increased in step with an ever-growing number of different materials. How an expansion into multiple segments impacts on the marketing and sales processes will be discussed in subsequent chapters.

\section{Market vs. Technology Segments}

Bachem, producer of peptides used in chemical and pharmaceutical research, served two major user segments, namely the research segment and the good manufacturing practices (GMP) segment, intended for use in pharmaceutical products. Although the two segments operated under different rules, the company could still leverage its technology across both.

For the research segment, Bachem's original market entry, no GMP specifications were required since these products were not for human consumption. This was a catalog business organized around basic building blocks. The peptides ordered for research could also be client specific. Main customers were university and pharmaceutical research departments. Business was conducted through a catalog and the product line topped 6,500 items.

The GMP segment, or pharmaceutical products segment, accounted for about 90 percent of Bachem sales. These peptides were intended for medication for humans. They could be used in clinical studies, either for phase I, II or III. Once specified for a trial, sales are stable. The product was owned by the pharma client and typically was custom-made. Sales were made under supply agreements, a forecast made by the purchasing customer, and included supply chain management commitments. Growth in this sector was directly dependent on pharmaceutical and biotech companies' research activities and clinical trials for new products. ${ }^{11}$

Technologically, the market for peptides was divided into synthetic peptides and biologically derived peptides. Bachem was traditionally a synthetic peptide

\footnotetext{
${ }^{10}$ Adapted from Sefar company profile.

${ }^{11}$ Adapted from Bachem company profile.
} 
producer. With its business growing, Bachem attempted to enter the market for biologically based peptides given the similarity and overlap of its customers.

\begin{abstract}
The market for peptides was divided into two major users, as well as two technology segments. At one time Bachem tried to enter the biologically based sector but had failed and was now limiting itself to synthetic peptides only. There were significantly different manufacturing processes between the two areas, with biologically derived peptides dominated by companies such as Novo of Denmark. The same limitations applied to the entry into the synthetic field by biologically based companies, such as Lonza, who unsuccessfully tried to enter the synthetic sector. The result was essentially two classes of competitors who did not directly compete with each other. ${ }^{12}$
\end{abstract}

The experience of Bachem, and other players in the peptide industry, demonstrates the limitations of segment expansion. As documented by other multiple segment firms, the requirement for success was closely linked to the exploitation of a common technology. Even when the customer base was the same, the players could not leverage successfully across technology boundaries.

\title{
Selecting Quality and Premium Price Segments
}

Most markets are characterized by some form of price or quality segmentation. Typically, the lower price segments yield higher volumes, but require a more costcompetitive supplier. Many of the Swiss SMEs are not cost leaders and attempt to make up for their cost disadvantage through moving into the top-quality and premium price segments. When doing so, it will be necessary to demonstrate, or support, quality claims with relevant information. The challenge then becomes how to operationalize the quality differential such that the price differential is more than compensated for. Caran d'Ache offered an example how to achieve this:

\begin{abstract}
With its prices about 20 to 25 percent above major competitors, Caran d'Ache was challenged to justify its price premium in terms of superior quality. Only perfection in its products allowed it to render a lifetime guarantee for its writing instruments. The company combined sustainability processes with superior quality and was able to claim superior quality along a number of dimensions. Its built-in 'airbags' worked as shock absorbers when pencils are dropped. Single pencils could be ordered to refill its boxes and the pencils boxes themselves could be reused for other purposes. The company used twice as much gold as its competitors to plate and emboss its pens, as well as offering repairs or refills. All of these elements contributed to lowering the lifetime cost to the user while adding superior functionality and durability. ${ }^{13}$
\end{abstract}

The optical component supplier Mikrop deliberately chose to pursue a premium quality and specifications segmentation, staying away, on purpose, from the lowerquality, albeit high-volume, segments, which were crowded with many competitors.

\footnotetext{
${ }^{12}$ Ibid.

${ }^{13}$ Adapted from Caran d'Ache company profile.
} 
Soon after its launch in 1981, Mikrop quickly positioned itself as one of the leading providers of specialized micro-optics for industrial image processing and medical technology applications. Mikrop focused on high-end optics with a diameter between $0.3 \mathrm{~mm}$ and $15 \mathrm{~mm}$ and was widely regarded as a top-quality manufacturer in the industry, where only a handful of companies worldwide could offer micro lenses of matching quality. This systematic focus on a global niche proved to be the right strategy. Mikrop realized that the company's strength was in optics of very small diameters and also realized early on that it did not make sense to go into other, less specialized segments with fierce competition. The company focused on high quality products paving the path to a position as one of the most sophisticated suppliers of high-precision optics globally. Due to the relatively small size of Mikrop's niche, bigger players were reluctant to enter its market. ${ }^{14}$

Key to a successful niche strategy is its relatively small size, rendering it unattractive to larger players. By concentrating on the small niche, and by delivering a full product line to service to that segment, the niche player can always outdo the generalist by offering products in every possible variation.

\section{Moving into High-Volume Segments}

Pursuing high-end segments, both in terms of quality and function, worked for most of the SMEs covered in this research. There were, however, also exceptions, such as Burckhardt Compression's successful strategy of demonstrates. The company found itself competing mostly in a small segment, leaving the majority segment to larger international competitors.

The global installed base of high-performance compressors was estimated at about 75,000 installations. Burckhardt's installed base amounted to about 5,500 operating compressors, made up of 300 hyper compressors of the highest performance in terms of pressure, as well as about 4,700 labyrinth compressors and 500 process gas compressors, all made by the company itself. In addition, some 70,000 process gas compressors were in use worldwide made by competitors, mostly large international firms.

Burckhardt did not really compete in the process gas compressor market. CEO Vogt convinced his team to move into this lower segment that was very large and could be considered a must win segment for Burckhardt. Entering this segment meant selling to for Burckhardt novel user segments, the Oil \& Gas, refinery and chemical sectors. Burckhardt could leverage its oil-free technology and vibration-reducing models where the company possessed a unique advantage. ${ }^{15}$

Burckhardt Compression entered the higher-volume gas process compressor market with the technology of its top-of-the-line high-performance machines. This way the company avoided building a lower-quality piece of equipment, steering clear of a trading down strategy. The move turned out to be highly successful and contributed substantially to later growth.

\footnotetext{
${ }^{14}$ Adapted from Mikrop company profile.

${ }^{15}$ Adapted from Burckhardt Compression company profile.
} 


\section{Niche-Within-Niche Segments}

DC Swiss, a specialist tool manufacturer located in the Jura region, epitomizes the execution of a niche strategy that is so delineated and chiseled, that it qualifies for the niche-within-a-niche, or focus-within-focus description. The company specializes in threading technology. Threading was a manufacturing process; threading tools were used to create screw threads. Compared to other manufacturing processes, such as milling or turning, threading was more complex.

Throughout its history, DC Swiss remained focused on threading technology and the tools needed to produce high quality threads for demanding applications. Threading tools were a niche in a much larger space of all kinds of cutting, machining, grinding, drilling, reaming, and milling tools. DC Swiss competed with a number of larger companies and was the only Swiss company focused exclusively on threading. Competitors were larger, but often carried a more limited number of threading tools. Threading technology competitors existed in Germany and Italy, a few specialists operated in Japan, but no direct competitors came from the US. There were also some broad-based global tool manufacturers, that did not specialize in threading and carried basic threading tools only. ${ }^{16}$

With a sales volume of less than CHF 30 million focused entirely on the threading segment of the large, global, tool market, further subsegmenting would seem to be unnecessary. However, the company embarked on a segmentation with even more granularity to provide more focus to its operation.

DC Swiss adopted a strategy of focus-within-focus by dividing its business into two parts. DC Thread was the unit tasked with pursuing standard applications for standard sized threads of $3 \mathrm{~mm}$ and larger, including some MEGA applications of up to $160 \mathrm{~mm}$. Part of the product portfolio of this unit were a complete range of taps, roll taps, thread mills and thread whirls for the full range of materials from stainless steel to composites. The company offered several thousand different products in this segment. ${ }^{17}$

DC Nano was the new unit tasked with pursuing threading technology for sizes of $0,3 \mathrm{~mm}$ to $3 \mathrm{~mm}$. These smaller diameter threads were viewed as contributing more value-added, resulting in better margins for the company and safer from copying by competitors. DC Nano could offer the full range of tools, such as thread cutting, thread forming, thread whirling, plug gauges and thread ring gauges, including soft rigid tapping and tapping chucks, all focused on the small diameter segment. DC Nano had a product portfolio of several hundred items. These tools were sought after by watchmaking, aerospace, optical, automotive, energy and medical sectors. ${ }^{18}$

The DC Swiss strategy of taking a subsegment and concentrating even more on the nano-sized segment by moving to where few competitors were willing to follow meant developing an expanded product line of several hundred specialty tools.

\footnotetext{
${ }^{16}$ Adapted from DC Swiss company profile.

${ }^{17}$ Ibid.

${ }^{18}$ Ibid.
} 
Added to the thousands of tools from its standard segment, the company is an example of the cramming the market space strategy that makes it very hard for larger competitors to follow. The dual approach was made possible through the common manufacturing and technology strategy serving both segments.

An astute reader will probably raise the question of critical mass, whether a company did not need to be of a certain size to compete. The question may have to be posed differently: Is it critical mass per company or is it per segment? Although one of the smaller tool companies competing worldwide, DC Swiss had giant status when it came to the threading segment; it had even more so when looking at its product line relation to others in the nano-threading tool segment.

\section{Organizing Around Segment Choices}

The previously cited example of DC Swiss makes clear that if several segments were served, dedicated organizational units could provide traction to the focus strategy. Breaking out DC Nano from DC Thread within DC Swiss allowed for the yet smaller but new product line to be given sufficient internal attention in order to grow and not to get pushed aside by concerns of the dominant segment.

This close connection between focus, segment selection, and company organization could also be observed at LEM.

Although LEM was focused on selling components, or transducers, only, the company had built up over time a wide range of industry sectors where company or product specific components were sold. Railroad and track side applications were the first segments penetrated. Later on, industrial applications, such as for robots, for energy and automation, eclipsed the rail sector. More recently, the automotive sector was gaining in importance. In response to this development into multiple segments LEM reorganized itself by separating the automotive component business from other industry applications. Although initially accounting for only about CHF 5 mio in sales, the segment grew faster than other parts of the business and reached CHF 50 mio by 2018, accounting for about 20 percent of LEM sales. ${ }^{19}$

The experience at LEM, DC Swiss, and other companies suggests that focus or market segment selection strategies alone will not be fully successful unless followed-up with organizational changes that provide sufficient attention to emerging segments.

\section{Observations on Segmenting}

This section moved from focus, or market space selection, to segmenting the space and, eventually, picking specific segments for targeting. It is important to understand that focusing on a market space (e.g., industry, market, technology, customer

${ }^{19}$ Adapted from LEM company profile. 
franchise, or solution) alone is not sufficient, but an SME also needs to further narrow its range of activities on a few coherent market segments.

Companies may employ creative ways of defining their chosen market space and its dimension for segmentation. Such creativity, or market vision, helps in defining specific segments for action. Insights for segmentation stem from a unique definition of the market space dimensions. To the extent that a company may have adopted a nonstandard way of defining the market space dimension, a company can earn a competitive advantage. Multiple segments may be selected as long as they stem from the same market space, otherwise dilution of effort may occur.

SMEs gain from narrow definitions of the chosen segment, or segments, when they follow-up with a market-cramming approach, filling their chosen segment with a large number of product variations, or models. By dint of such a strategy with a more dedicated, more refined offer, the SMEs can outperform their larger competitors that do not specialize within the selected segments. In this David vs. Goliath battle, SMEs can achieve higher market share and sustain their market position in the chosen segment. Reversing the tables, David actually becomes Goliath.

Open Access This chapter is licensed under the terms of the Creative Commons Attribution 4.0 International License (http://creativecommons.org/licenses/by/4.0/), which permits use, sharing, adaptation, distribution and reproduction in any medium or format, as long as you give appropriate credit to the original author(s) and the source, provide a link to the Creative Commons license and indicate if changes were made.

The images or other third party material in this chapter are included in the chapter's Creative Commons license, unless indicated otherwise in a credit line to the material. If material is not included in the chapter's Creative Commons license and your intended use is not permitted by statutory regulation or exceeds the permitted use, you will need to obtain permission directly from the copyright holder.

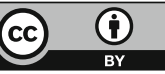

